\title{
The Superwoman Trope - An Analysis on Excessive Masculine Woman Superheroes in Movies, Anime, and TV Shows
}

\section{David Sunil}

Department of English, Sivananda Sarma RV Memorial College, Bengaluru, India

Received: 11 Nov 2020; Received in revised form: 13 Dec 2020; Accepted: 20 Dec 2020; Available online: 28 Dec 2020

(C)2020 The Author(s). Published by Infogain Publication. This is an open access article under the CC BY license

(https://creativecommons.org/licenses/by/4.0/).

\begin{abstract}
The Superwoman ideology of superheroes has long been elusive in the cinematic medium (Movies, $T V$ shows and Anime) as well as the print medium (graphic novels, comics and manga). However, this elusiveness is not due to the fact that patriarchy has a role to play in its propagation but it is because the Superwoman (or Tough Girl) trope has long been used, reused and overused to the point it is no longer a matter of elusiveness or careful insertion in the mainstream cinematic or print mediums. Instead of subtly portraying a strong woman character that embraces her calm and composed feminine side counterbalancing it with her strong will and determination to overcome a given problem. Characters like Skyler White from the TV series Breaking Bad (2008-2013), Gal Gadot from (Wonder Woman (2017), Batman vs Superman (2016) and Justice League (2017)), Claire Underwood from the TV series House of Cards (2013-2018), Bulma \& Android 18 from the anime Dragon Ball Z (1989-1996) \& Dragon Ball Super (2015-present) and Mikasa Ackerman from the anime Attack on Titan (2013-present) are vital examples for this multiple layered woman tropes. In this research paper we will be looking into the dynamics behind the excessive masculinity that is employed for woman characters like Trinity from The Matrix Trilogy (1999-2003), Scarlet Johansson from The Avengers (2012-2019) series of movies, Caulifla and Kale from the Dragon Ball Super (2015-present) to name a few. In order for us to effectively ascertain what these gametes of women representations unfold, we need to analyze how these characters interact and portray their characters in tandem with the other male characters as well as the other lesser female characters in their respective movies, TV series or anime. After such a comparison or standard has been set between them and the other characters, then we can identify what are their motivations for acting a certain way. Strong woman characters and the overly masculine woman characters will both go through this comparison standard that this paper will attempt to put them through and only then can we safely call them a strong woman character or an overly masculine woman character. This paper will attempt to give a strong justification for both the categories of woman characters and try to understand them.
\end{abstract}

Keywords-Comparison, feminine, masculine, representation, superwoman trope.

\section{INTRODUCTION}

Women have long been misrepresented or have a very clichéd or one-dimensional arc within the narrative of a particular movie, anime or TV shows. This is especially true when it comes to women characters from Anime or Fantasy Movies, where the singular goal of the woman character would be to be either the conquest that the male protagonist or a group of men have to fulfil or solely for the love interest of the said male protagonist. In colloquial terms this would be termed as 'EYE CANDY'. However, this misrepresentation was slowly thwarted by the fact that the 'Tough Girl' trope was introduced where the woman 
represented in cinematic mediums such as Movies, Anime and TV shows saw a drastic change to the stereotypical and clichéd 'damsel in distress' idea of woman. Strong woman characters were created that had not just the physical prowess that rivals the men in the narrative as well as the intelligence (emotional and psychological) that was very rarely seen in movies. It is also important to understand that these strong women characters were created or introduced in order to thwart or subvert the idea of a weak and feeble woman character but ended up being just mimicking the men and not forming an identity of their own as strong woman characters. This paper will attempt to decipher the so called 'strong woman' characters and if they are fully rounded and flushed out characters representing the woman community as a whole or just another excuse for bland characters to serve a larger agenda.

\section{ANALYSIS ON THE VARIOUS CHARACTERS}

\subsection{The Quasi - Strong Women Characters}

When we talk about strong women characters portrayed in Cinematic mediums, there is one jarring problem that arises: 'How or what constitutes as strength of a woman character?' This is a question that even to this date has not been fully answered. The idea of the so called 'strong' woman characters are solely based on the physical capabilities that they can exude in the battlefield such as with characters like Caulifla and Kale from the Dragon Ball Super (2015-2018), Trinity from the Matrix Trilogy (1999-2003) and Black Widow from the Marvel Cinematic Universe series of movies Avengers (2012) \&Captain America: The Winter Solider (2014). Although this would seem like a good thing and a complete shattering of the 'damsel in distress' trope, it also seems like the idea of strength in a woman character solely hinges on their physical capabilities and have to become this masculine encased characters that have to embody characteristics of a man in order to be recognized and/or taken seriously as a character. This however proves to be futile when all they can do is punch and fight equal if not better to than the men in the given narrative.It becomes very redundant to see such generic and uninteresting or bland character depth when this concept of strong woman characters are just being introduced and being appreciated by the general population. It seems more forced when woman characters do not exude any sort of intelligence of use their wits to solve the problems within the narrative and is just another muscle bound fighter that is essentially a character that aids the main male protagonist and serves no other role in the narrative beyond that.

\subsection{The Full - Dimensional Women Characters}

In this instance, we see a complete paradigm shift of how strong woman characters are supposed to be represented or how it fits into the narrative structure that they are a part of. In the instance of TV shows, the character of Skyler White from the critically acclaimed Breaking Bad (2008-2013) who is shown to be the perfect counter and a constant thorn in this way for Walter White, not in the physical sense, but a mental and intelligent barrier to all his antics. This was also not taken too kindly by the fans of the show as well as the general public and the hatred for such a well-crafted and well written strong woman character was readily directed to even the actress who played the role Anna Gunn. Claire Underwood from the TV series House of Cards (2013-2018) also embodies this characteristic of being the ambitious, power hungry and successful pillar of support to the male protagonist at the same time always being the influencer of her husband rather than being the sidekick, having her own identity or struggling to keep up with her own ambitions and that of her husbands, sometimes even regretting being by his side. On the other spectrum of Anime, characters like Bulma and Android 18 from the Dragon Ball (1989-1996)and Dragon Ball Super (2015-2018) franchise, Mikasa from Attack on Titan (2013-present) exhibit both the physical prowess to stand toe to toe if not even surpass the men of the narrative but also show their softer and more human side sometimes utilizing their wits more than their brute strength even if they can. This is especially true with characters like Bulma who has no physical prowess but is a scientist and strong willed so much so that all the male characters of the narrative stop and listen to her because of her commanding presence and it is solely achieved by her wits and intelligence and not by the brute strength that the other so called quasi-strong woman fail to do. It also makes sense for her as a character and fits into the narrative perfectly.

\section{REVIEW OF LITERATURE}

The first paper,No Panties! Censoring Male and Female Characters in Three Popular Anime Shows Aired in the US and Latin Americaby Hernandez Josephy and Daniel E talk about the act of censoring and filtering supposed obscenity with the woman characters in the three popular anime that was broadcast in North and South America. The second paper, Folktales and Other References in Toriyama's 
Dragon Ball by Xavier Lopez Mínguez deals with the aspect of traditional Japanese folklore and traditions being implemented in the most popular manga and anime Dragon Ball by Akira Toriyama. The third paper, Gender Portrayal in the Marvel Cinematic Universe by Jess Ameter deals with the way in which women are perceived and interact with the supposedly superior male characters in the most popular comic book movie adaptations of the Marvel cinematic universe. The fourth paper, Gender Portrayal in Marvel Cinematic Universe Films: Gender Representation, Moral Alignment, and Rewards for Violence by Kristen Ray deals with the perception of the female superheroes in the Marvel movies as well as how in-depth this representation affects the morality of the woman characters as a whole. The fifth paper, Influence and Importance of Cinema on the Lifestyle of Educated Youth: A study on University Students of Bangladesh by Istiak Mahmood deals with the visual narrative being cinema, affecting the lives of students and the youth, especially in the Bangladeshi context also on how it affects their lifestyle. The sixth paper, Super Heroes and Gender Roles, 1961-2004 by E. Palmer talks about the transition of the superhero trope and the issues of gender that it dealt from the time that superhero genres as a visual narrative began to take its hold in Popular Culture. The seventh paper, The role of women in film: Supporting the men -- An analysis of how culture influences the changing discourse on gender representations in filmby Nichole Jocelyn Murphy deals with the concept of how the idea that woman characters in superhero movies were only as supporting characters but then later evolved to a more influential role as the changing society in real life and the cultural change aided it. The eighth paper, The Rise of the Super Sidechicks: An Analysis of Girls in Superhero Filmsby Ashley Dorothy Hendricks talks about the various superhero movies using the sidekick aspect of the movie to integrate woman into the foyer by end up actually inhibiting their growth both as a character and through what they are ultimately trying to portray. The ninth paper, BADASS BITCHES, DAMSELS IN DISTRESS, OR SOMETHING IN BETWEEN?: Representation of female characters in superhero action filmsby Jenni Kinnunen deals with the aspect of woman being too weak to fight on their own and needed to be rescued and at the same time the other dimension of woman being a complete full-fledged fighter and being a 'strong' character as a whole and which of these aspects of woman in movies is seen to be more favorable. The tenth paper, Super or Sexist? The Evolution of Female Superheroes in Comics and Filmby Jordon Gablaskitalks about if the representation of oversexualized woman characters throughout the years of movies with female superheroes is seen as a necessity or if it is extremely sexist and biased in its approach. The fourteenth article, Raiding the Superhero Wardrobe: A Review of The Superhero Costume-Identity and Disguise in Fact and Fiction: The Superhero Costume-Identity and Disguise in Fact and Fiction by Alke Gröppel-Wegenerdeals with the symbolism, the realism and the spectacle of superhero costumes that are presented in the movies and how they are a reflection of the real life thing and how much it draws parallels to the real world. The fifteenth paper, Fantasy, gender and power in Jessica Jones by Stephanie Green deals with the role of Jessica Jones who is the lead female superhero character in the TV series that struggles to embrace her powers and abilities while having to deal with the psychological and sexual trauma that she had to undergo, it also reflects on the conventional ideas that are set in the movie genre on woman with a feminist approach and also tries to bring in woman directors and actors into realm of filmmaking.

\section{CONCLUSION}

As evidence suggests, in order for a character, especially a strong woman character to fit into the narrative of the cinematic medium being movies, TV shows and anime there has to the element of creating the woman character in a way that is both physically strong and at the same time has the wits and intelligence to outmaneuver the male protagonists who do not have to need to exhibit a strong character moment of character trope due to the power struggle that exists in the patriarchal society, especially seen in the cinematic mediums. There is also an important point that needs to be addressed that paper and presentation does not wish to portray that strong woman characters have to not show their physical strength and match men in that spectrum but to purely show that in a narrative standpoint it does not bode well as it would make the woman character that has already been tarnished and beat down over the years with one dimensional character development to again fall into that same trap of creating so called 'strong' woman characters but one dimensional in nature. Thus creation of the multilayered and complex characters that both fit into the narrative well, compliments and plays a role and character of their own and creating an identity of their own within the story is something that the fully rounded well-written woman characters always achieve. It is thus the duty and responsibility of the filmmakers and animators to dwell deep 
into a character of woman, especially the strong woman characters and create this full-rounded and complex characters and not just an excessive masculine male replacement strong woman characters for the sake of inserting it in the movie, TV show or anime just because the society demands it. This has to be done so that the misrepresentation that woman characters have undergone all throughout the years will be full subverted and that subversion will now hold that much more power and be etched in audiences and fans alike.

\section{REFERENCES}

[1] Josephy-Hernández, Daniel E. (2015). No Panties! Censoring Male and Female Characters in Three Popular Anime Shows Aired in the US and Latin America. 10.13140/RG.2.2.24063.82083.

[2] Mínguez López, Xavier. (2014). Folktales and Other References in Toriyama's Dragon Ball. Animation. 9. 27. $10.1177 / 1746847713519386$.

[3] Ameter, Jess. (2019). Gender Portrayal in the Marvel Cinematic Universe. Undergraduate Research Journal. University of Colorado at Colorado Springs. Vol. 12, No. 2. Pg.: 53-59.

[4] Ray, Kristen. (2020). "Gender Portrayal in Marvel Cinematic Universe Films: Gender Representation, Moral Alignment, and Rewards for Violence". Brigham Young University. BYU ScholarsArchive. Theses and Dissertations. 8528.

[5] Mahmood, Istiak (2013). Influence and Importance of Cinema on the Lifestyle of Educated Youth: A study on University Students of Bangladesh. IOSR Journal of Humanities and Social Science (IOSR-JHSS) Volume 17, Issue 6, PP 77-80.University of Khulna. Bangladesh.

[6] Palmer, E. (2008). Super Heroes and Gender Roles, 19612004. Association for Education in Journalism and Mass Communication

[7] Murphy, Jocelyn Nichole. (2015). "The role of women in film: Supporting the men -- An analysis of how culture influences the changing discourse on gender representations in film". University of Arkansas, Fayetteville. Journalism Undergraduate Honors Theses. 2.

[8] Hendricks, Ashley Dorothy. (2013). The Rise of the Super Sidechicks: An Analysis of Girls in Superhero Films. School of Communication and Multimedia Studies. Florida Atlanta University. Boca Raton, Florida. United States of America.

[9] Kinnunen, Jenni. (2016). BADASS BITCHES, DAMSELS IN DISTRESS, OR SOMETHING IN BETWEEN?: Representation of female characters in superhero action films. Department of Languages. University of Jyväskylä. Finland.

[10] Gablaski, Jordan.(2020). "Super or Sexist? The Evolution of Female Superheroes in Comics and Film". Honors Theses. 84.
Digital Commons. Assumption University. Bangkok. Thailand.

[11] Sarkar, Srijita. (2012). "An analysis of Hindi women-centric films in India.". Electronic Theses and

Dissertations. Paper 1265. https://doi.org/10.18297/etd/1265.

[12] Shaikh, Fouzia. A., Azam, A.A.S. (2016). A Psycho-social Perspective of Gender Role of Then and Now Leading Ladies of Hindi Cinema. Amity University Rajasthan. Amity Journal of Media \& Communication Studies (ISSN: 2231-1033). Vol.6, No.1.

[13] Raza, Nudrat. (2015). Deconstructing Gender Roles in Bollywood Films: Through Women's Empowerment Development Discourse. Department of Society and Globalisation. Roskilde University. Roskilde, Denmark.

[14] Gröppel-Wegener, Alke.(2016). Raiding the Superhero Wardrobe: A Review of The Superhero Costume-Identity and Disguise in Fact and Fiction: The Superhero CostumeIdentity and Disguise in Fact and Fiction, B. Brownie and D. Graydon, Bloomsbury Academic, 192 pages, 15 b/w images, ISBN: 978-1472595904. The Comics Grid: Journal of Comics Scholarship, 8(1), 1.

[15] Green, Stephanie (2019). Fantasy, gender and power in Jessica Jones. Continuum, 33, 173-184. doi: 10.1080/10304312.2019.1569383.

[16] Shendurnikar, Nidhi. (2012). GENDER REFLECTIONS IN MAINSTREAM HINDI CINEMA. Global Media Journal. 3. 1-9.

[17] Sibal, Vatika. (2018). STEREOTYPING WOMEN IN INDIAN CINEMA. Scholarly Research Journal for Interdisciplinary Studies. 5. 10.21922/srjis.v5i43.11253. 